\title{
A model predictive control strategy for the space heating of a smart building including cogeneration of a fuel cell-electrolyzer system
}

\author{
Fabrizio Sossan ${ }^{\mathrm{a}, *}$, Henrik Bindner ${ }^{\mathrm{a}}$, Henrik Madsen ${ }^{\mathrm{b}}$, Dimitri Torregrossa ${ }^{\mathrm{c}}$, Lorenzo Reyes Chamorro ${ }^{\mathrm{c}}$, \\ Mario Paolone ${ }^{\mathrm{c}}$ \\ a DTU Elektro, Frederisborgvej 399, 4000 Roskilde, Denmark \\ ${ }^{\mathrm{b}}$ DTU Compute, Richard Petersens Plads, 2800 Lyngby, Denmark \\ ${ }^{\mathrm{C}}$ EPFL, DESL, 1015 Lausanne, Switzerland
}

\section{A R T I C L E I N F O}

Article history:

Received 21 February 2014

Received in revised form 20 May 2014

Accepted 22 May 2014

Available online 20 June 2014

\section{Keywords:}

Demand response

Control-by-price

Combined heat and power generation

Proton exchange membrane fuel cell

Model predictive control

Grey-box modelling

\begin{abstract}
A B S T R A C T
The objective of this paper is to analyze the value of energy replacement in the context of demand response. Energy replacement is defined as the possibility of the consumer to choose the most convenient source for providing space heating to a smart building according to a dynamic electricity price. In the proposed setup, heat is provided by conventional electric radiators and a combined heat and power generation system, composed by a fuel cell and an electrolyzer. The energy replacement strategy is formulated using model predictive control and mathematical models of the components involved. Simulations show that the predictive energy replacement strategy reduces the operating costs of the system and is able to provide a larger amount of regulating power to the grid. In the paper, we also develop a novel dynamic model of a PEM fuel cell suitable for micro-grid applications. The model is realized applying a grey-box methodology to the experimental proton exchange membrane fuel cell of the EPFL-DESL micro-grid.

(c) 2014 Elsevier Ltd. All rights reserved.
\end{abstract}

\section{Introduction}

In the recent years, flexible demand became of renewed interest as a promising resource to restore the lack of control capacity of the power system caused by the increase of the proportion of energy production from renewable generation. Flexible demand is that part of the consumption that can be shifted in time without compromising the quality of the primary services it is supplying to the consumers. The electric loads capable of flexible operation are said demand side resources (DSRs) and are, for example, the electric thermal loads such as space heating devices and refrigeration units; in this case, the flexibility is given by the associated thermal mass that allows a temporary deferral of the power consumption without causing significant variations of the temperature. The utilization of flexible demand has been proposed to support the primary control of frequency and voltage, and provide regulating power to the grid [1-8].

In this paper, we introduce the concept of energy replacement applied to the provision of space heating to a smart building. Energy replacement consists in coupling a traditional source of

\footnotetext{
* Corresponding author. Tel.: +45 51801557.

E-mail address: faso@elektro.dtu.dk (F. Sossan).
}

space heating, i.e. electric radiators, together with combined heat and power (CHP) generation units. The CHP source is a storage system composed by a proton exchange membrane fuel cell (PEMFC), an electrolyzer and tanks for storing the reactants. The control of the energy replacement setup is realized by means of model predictive control (MPC), which achieves to schedule the operation of the energy resources according to a dynamic electricity price and while respecting the temperature comfort of the consumer. From the power grid operation point of view, such a setup is expected to provide larger flexibility because energy can be stored not only in the building thermal mass, but also by producing and storing the reactants of the PEMFC-electrolyzer system. The electricity price reflects the need of regulating power of the grid, and, in general, is meant to act as an economic incentive for the flexible demand to shift the consumption. This approach is known as control-by-price, and is extensively advocated in existing literature as a simple framework to enable demand response, since it relies on a few ICT requirements. We show by simulation that, in comparison with conventional space heating setups [9-11], the proposed predictive control strategy achieves a reduction in the operation cost and is able to manage effectively the extended amount of flexibility provided by the CHP system. The topic of the integration of CHP devices at demand side level with the 
objective of enhancing the performance of demand response was previously considered in [12]. We extend such a development by including dynamic models of the fuel cell and building, showing, as mentioned above, how energy can be stored by means of both producing reactants and exploiting the thermal mass of the building envelope. In the process of developing the energy replacement strategy, we propose a novel dynamic model of a PEMFC suitable for micro-grid applications. The model is realized applying a grey-box modelling methodology and is identified using measurements from the experimental $15 \mathrm{~kW}$ PEMFC of the DESL facility at EPFL.

The paper is organized as follows: Section 'Methods' describes the setup of the replacement strategy, the models of the components and the MPC algorithm. In Section 'Results', the simulation results are presented and discussed. Finally, conclusions are stated in Section 'Conclusions'.

\section{Methods}

\section{The energy replacement concept}

The objective of the energy replacement strategy is to provide heat to a smart building combining the operations of several energy resources while minimizing the total cost of the operation and according to the requirements of the grid, which reflects its need of regulating power into a dynamic price of the electricity. The configuration of the energy replacement setup is sketched in Fig. 1: space heating is supplied by the electric radiators and recovering the waste heat associated to the electrochemical conversions operated by the FC and electrolyzer. From Fig. 1, the reactants required by the FC are produced by the electrolyzer, and are mechanically compressed by electric compressors and stored in tanks. It is worth to note that high pressure electrolysis could avoid the use of the compressors since the reactants are already produced at high pressure [13]. Although, in this setup, the configuration with mechanical compression is chosen because is more general in terms of components.

The control of the energy replacement strategy is realized using the MPC. It consists in an optimization problem that minimizes the associated penalty function, while obeying the constraints of the system. The formulation of the MPC strategy requires the mathematical models of the components in Fig. 1. The model of the FC is identified using a grey-box approach and using measurements from a $15 \mathrm{~kW}$ PEMFC: the modelling methodology, the experimental setup and the model are described in Section 'Fuel cell grey-box model'. The models of the compressors and tanks of the reactants are realized using a first principles approach and are described in Sections 'Tank model' and 'Compressor model', respectively. The mathematical models of the electrolyzer and building are from

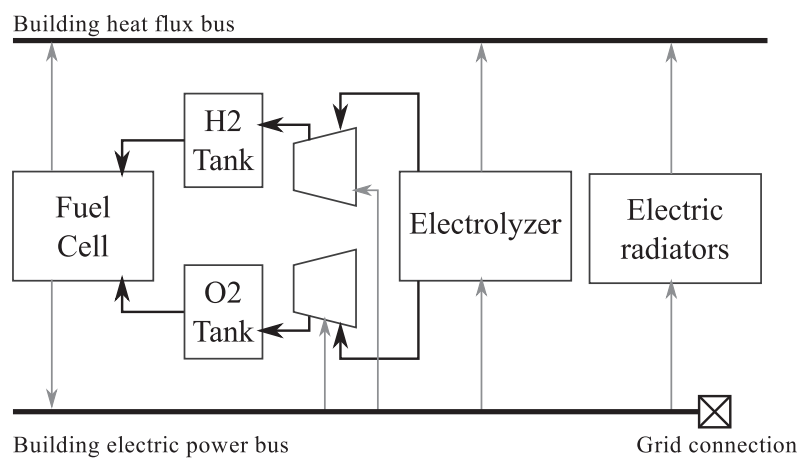

Fig. 1. The setup of the energy replacement strategy. Building space heating is provided by conventional electric radiators, the FC and electrolyzer. The reactants are mechanically compressed and stored in the tanks. literature and are presented in Sections 'Electrolyzer model' and 'Building thermal model', respectively. The formulation of the MPC problem is described in Section 'Energy replacement model predictive control'.

\section{Fuel cell grey-box model}

\section{Stochastic grey-box modelling}

The PEMFC model is identified using the grey-box methodology, which is a framework that allows to identify a model incorporating its physical knowledge together with measurements from a real device. The adopted grey-box modelling process consists in formulating a candidate model as a function of unknown parameters that are estimated from measurements using maximum likelihood estimation (MLE). The objective of MLE is determining the parameters of the model that maximize the likelihood of the model, i.e. maximize the probability that the model can explain the set of available measurements. The mean and variance of the 1-step ahead prediction of the candidate model with parameters $\theta$ at the time step $k$ are defined as

$\hat{\boldsymbol{y}}_{k \mid k-1}=E\left[\boldsymbol{y}_{k \mid k-1}(\boldsymbol{\theta})\right]$,

$R_{k \mid k-1}=\operatorname{Var}\left[\boldsymbol{y}_{k \mid k-1}(\boldsymbol{\theta})\right]$,

respectively, where $\boldsymbol{y}_{k \mid k-1}$ indicates the prediction of the model provided the information up to $k-1$. The 1 -step ahead prediction error of the model is defined as

$\boldsymbol{\epsilon}_{k}=\boldsymbol{y}_{k}-\hat{\boldsymbol{y}}_{k \mid k-1}$,

where $\boldsymbol{y}_{k}$ is the measurement at the time interval $k$. Assuming that the predictions of the stochastic model are Gaussian distributed, the likelihood function is defined as

$L(\boldsymbol{\theta}, \boldsymbol{y}(k))=\left(\prod_{j=1}^{k} \frac{\exp \left(-\frac{1}{2} \boldsymbol{\epsilon}_{j}^{T} R_{j \mid j-1}^{-1} \boldsymbol{\epsilon}_{j}\right)}{\sqrt{\operatorname{det}\left(R_{j \mid j-1}\right)} \sqrt{2 \pi}^{k}}\right) p\left(\boldsymbol{y}_{0} \mid \boldsymbol{\theta}\right)$,

which is the joint probability of the prediction errors obtained as the product of the single conditional probability density. The parameters of the model are found by minimizing the logarithm of the function in Eq. (4). The MLE routine that is utilized to estimate the FC model is implemented in the software package CTSM [14], which is available as a library for the programming language for statistical computing $R$. In order to capture all the dynamics inherent the system to identify, the device to model should be excited in a wide range of frequency during its operation. This is usually accomplished by controlling the device using a pseudo binary random signal (PRBS), that is a binary signal with a fixed period and duty cycle randomly picked from an uniform distribution. In the case of the FC, the PRBS was replaced by a stepwise signal (shown in Fig. 2) characterized by random durations and amplitude variations. Once the parameters are estimated, the candidate model is validated by means of performing the residual analysis, which allows to determine if the model is able to capture all the dynamics observable in the set of measurements. The FC dynamic model is formulated using stochastic differential equations (SDEs), which allow to obtain, as an outcome of the estimation process, the uncertainties related to both the system disturbances and measurements noise. In general, this is a useful feature since a characterization of the disturbances allows to determine the statistics of the predictions of the model and implement Kalman filtering for state reconstruction and prediction. In the following sections, the experimental setup and the FC model are described.

\section{Experimental setup}

DESL laboratory at EPFL in Lausanne implements an experimental micro-grid for studying the interaction between distributed 

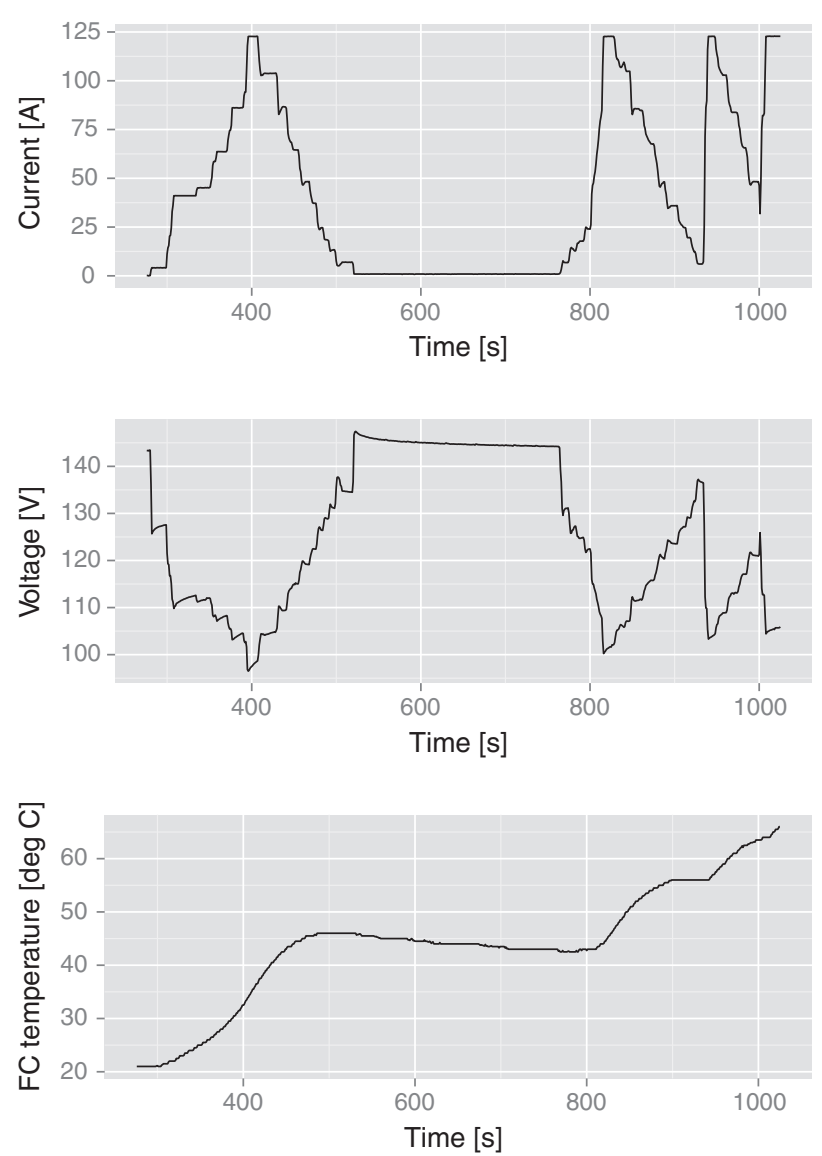

Fig. 2. The measurements used to estimate the FC model. The three plots show the FC current (that is controlled by the electronic load), the DC voltage and the temperature of the stack, respectively.

power generation and the electric power system. The micro-grid is composed by a number of distributed energy resources, among which a $15 \mathrm{~kW}$ PEMFC. The FC system, originally developed for automotive application, is composed by the supply system of the reactants, the FC and the associated cooling system. All the components of the FC system are controlled and supervised by an internal controller, which is accessible through a CAN bus and returns information regarding the state of the system, temperature and voltage of the stack, and maximum current that the FC can deliver. The FC is supplied by a 240 and $480 \mathrm{~m}^{3}$ tanks at 200 bar for hydrogen and oxygen, respectively, for an equivalent of $1 \mathrm{MW} h$ of stored energy. A further pipeline provides nitrogen to the FC, that is used to purge the reactants circuit and the membrane after each use. The electric output of the FC is connected to a programmable direct current (DC) load. All the measurements are sampled at $10 \mathrm{~Hz}$ and are logged by a software in LabView, which is also used to set the current consumption reference of the DC load. The experiment requirements are to measure the FC stack terminal voltage, FC stack temperature and to control the current supplied by the FC by means of the electronic load, in a similar way as done in [15]. The FC measurements that are used to identify the model of the $\mathrm{FC}$ are shown in Fig. 2.

\section{Model formulation}

In a $\mathrm{FC}$, the not unitary efficiency of the electrochemical conversion causes a drop of the voltage available at the terminals of the stack. The voltage of a PEMFC can be described by the equivalent electric circuit shown in Fig. 3, where $E$ is the modified Nerst potential and $v_{\text {act }}, v_{\text {conc }}, R_{\text {ohm }}$ are the activation loss, concentration

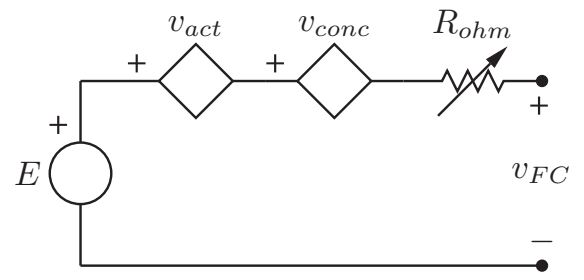

Fig. 3. The conventional description of the FC stack voltage [16].

loss and ohmic loss, respectively [16]. All the three types of voltage losses depend on the FC temperature and reactants partial pressures. Activation and concentration losses are evident at low and high values of the FC current, respectively, while ohmic loss is linear with the current.

As far as the dynamic properties of PEMFCs systems are concerned, the dominant time constants are those associated to the temperature evolution of the FC stack $(O(2))$ and operation of the supply system of the reactants $(O(0))$, while the electric dynamics are very fast $(\ll O(-3))$ [17]. In the existing literature, dynamic models of PEMFCs systems were developed mainly in connection to automotive applications, and they describe how the FC voltage is affected by the dynamics of the supply system [18-24]; in such models, the temperature dynamics are disregarded as it considered that the FC is operating in continuous mode, hence with the temperature regulated at the nominal value by an active cooling system. In the case of CHP applications, the dominant time constants of the system are those associated to the temperature dynamics of the building, i.e. $O\left(10^{4} \mathrm{~s}\right)$. In this context, the dynamics of the supply system of the reactants can be neglected since they are much faster than the dominant time constants. On the contrary, the thermal transient is of longer duration and should be taken into account, especially if the FC is meant to operate in a discontinuous mode, as it is the case of the proposed energy replacement strategy. These requirements motivate the need of developing a new dynamic grey-box model for PEMFC systems specific for micro-grid applications. The developed model of the FC is composed by two parts: a static model that describes the voltage of the FC as a function of the FC current and temperature, and a dynamic model that describes the temperature evolution of the FC stack.

Model of the FC stack terminal voltage. The model proposed to describe the voltage of the PEMFC is shown in Fig. 4. The ideal voltage source $O C V$ denotes the open circuit voltage, while the controllable voltage source $v_{\text {act }}$ and resistor $R_{\text {ohm }}$ denotes the activation and ohmic losses, which are a nonlinear and linear functions of the FC current $i_{F C}$, respectively. At this stage, the concentration loss is not modelled because it was not observable in the set of available measurements (indeed the maximum FC DC current was below $120 \mathrm{~A})$.

The mathematical formulation of the model corresponds to the KVL applied to the circuit in Fig. 4, that is:

$v_{F C}=O C V-v_{a c t}-R_{o h m}$.

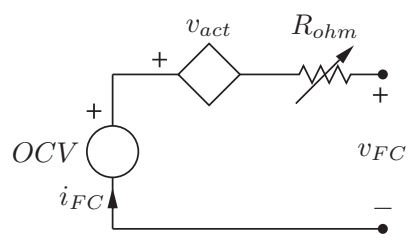

Fig. 4. The proposed model of the FC stack voltage. 
In the model, the value of $O C V$ is chosen as a constant because no clear correlation with the temperature was observed in the measurements. Theoretically, the OCV of a single cell is defined by the modified Nernst potential [25], which is given as

$$
\begin{aligned}
E^{\prime}\left(T_{F C}, p_{H_{2}}, p_{O_{2}}\right)= & 1.229-0.85 \times 10^{-3}\left(T_{F C}-298.15\right) \\
& +4.3085 \times 10^{-5} T_{F C}\left[\ln \left(p_{H_{2}}\right)+\frac{1}{2} \ln \left(p_{0_{2}}\right)\right],
\end{aligned}
$$

where $T_{F C}$ is the temperature $[\mathrm{K}]$ of the stack, $p_{\mathrm{H}_{2}}$ and $p_{\mathrm{O}_{2}}$ are the partial pressures [atm] of hydrogen and oxygen, respectively. The derivative of Eq. (6) with respect to the temperature, calculated at the operational value of the reactants pressure and zero current (2.50 atm and $2.55 \mathrm{~atm}$ for oxygen and hydrogen, respectively), gives a value of approximately $0.8 \times 10^{-4} \mathrm{~V} \mathrm{~K}^{-1}$ : the linear dependency of the modified Nerst potential with the temperature is very small, thus assuming a constant value for OCV in Eq. (6) is reasonable. Even if the number of the FC cells composing the stack might be known, it can be inferred by the following expression:

$n_{F C}=\frac{O C V}{E^{\prime}}$,

where $E^{\prime}$ is as in Eq. (6).

A candidate function for describing the activation loss $v_{\text {act }}$ of Eq. (5) is the Tafel's equation:

$v_{\text {act }}=a \cdot \ln \left(i_{F C}\right)-b$,

where $a$ and $b$ are two coefficients to be determined empirically $[18,26]$. In the proposed model, we assume that the coefficient $b$ does not depend on the temperature, so it can be considered as part of the FC OCV; moreover, we replace the Tafel's equation with the following one

$v_{a c t}=a^{\prime} \cdot \sqrt{i_{F C}}$

which is a function of similar shape as Eq. (8), but is defined over the whole set of possible values of the FC current, i.e. $i_{\mathrm{FC}} \geqslant 0$; this is done with the objective of avoiding numerical instability of the algorithm that estimates the parameters of the model. In order to account for the temperature dependency of the activation loss, the parameter $a^{\prime}$ of Eq. (9) is replaced by a linear function of the FC temperature. Hence, the final expression that describes the activation loss is given as

$v_{a c t}\left(T_{F C}, i_{F C}\right)=\left(\alpha \cdot T_{F C}+\beta\right) \sqrt{i_{F C}}$

where $\alpha$ and $\beta$ are parameters to be estimated.

The ohmic loss associated to the FC operation is described by a resistance; in a similar way as done for the activation loss, we describe the resistance as a linear function of the temperature. The ohmic loss is given as

$R_{\text {ohm }}\left(T_{\mathrm{FC}}\right)=\gamma \cdot T_{\mathrm{FC}}+\delta$,

where $\gamma$ and $\delta$ are parameters to be estimated.

Model of the FC temperature. The equivalent electric circuit that describes the evolution in time of the FC temperature $T_{F C}$ is shown in Fig. 5 , where $Q_{F C}$ is the heat generated by the electrochemical

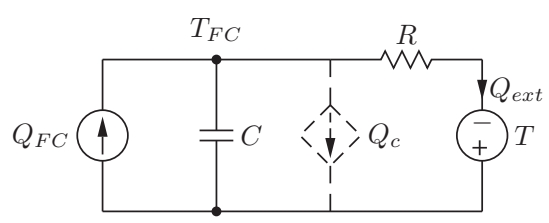

Fig. 5. The model proposed to describe the temperature dynamics of the FC. The current generator $Q_{c}$ is sketched with the dashed line because it is not considered in the identification process. conversion, $C$ is the lumped thermal capacity of the FC, $R$ is the lumped thermal resistance of the FC envelope, while $Q_{\text {ext }}$ is the heat loss due to conduction and natural convection that occurs between the FC and the environment, which is at temperature $T$. The controlled current generator $Q_{c}$ of Fig. 5 denotes the heat extracted by the FC cooling system, which is thermostatically controlled and is activated once the temperature of the FC reaches the nominal operating value of $\approx 80^{\circ} \mathrm{C}$; in order to reduce the number of variable to identify, the quantity $Q_{c}$ is excluded from the estimation process by means of using a set of measurements where the cooling system is off, i.e. with $T_{F C}<80^{\circ} \mathrm{C}$.

The first order differential equation that describes the circuit of Fig. 4 constitutes the deterministic skeleton of the FC thermal model. The complete formulation of the thermal model of the FC is given as

$d T_{F C}(t)=\left(\frac{Q_{F C}}{C}-\frac{T_{F C}(t)-T(t)}{R C}\right) d t+\sigma d B(t)$

where $B(t) \in \mathcal{N}(0,1)$ is a Wiener process, i.e. a stochastic process with independent normal distributed increments, and $\sigma$ is a scale coefficient to estimate. By combining Eqs. (10) and (11), the amount of heat $Q_{F C}$ generated by the FC corresponds to the Joule losses associated to the voltage generator $v_{\text {act }}$ and resistance $R_{\text {ohm }}$ of Fig. 4, and is given as

$Q_{F C}\left(T_{F C}, i_{F C}\right)=\left(\left(\alpha \cdot T_{F C}+\beta\right) \sqrt{i_{F C}}+\left(\gamma \cdot T_{F C}+\delta\right) i_{F C}\right) i_{F C}$.

Identification results. The parameters of the electric model and thermal model are estimated using the procedure described in Section 'Stochastic grey-box modelling'. In order to provide a warm start to the optimization underlaying the MLE problem, the parameters of the electric model are previously estimated using measurements of the voltage, current and temperature of the FC and applying conventional least squares. The estimated values of the mean and standard error of the parameters of the FC model are summarized in Table 1.

As a support to the validation process of the model, we perform the residuals analysis, which consists in evaluating any autocorrelation in the 1-step ahead prediction error of the model, or residual, that was defined in Eq. (3). In the ideal case, the prediction error should be white noise, meaning that the model was able to capture all the dynamics observable in the measurements. Fig. 6 shows the autocorrelation function (ACF) of the predictions of the model (black profile) and the $90 \%$ confidence interval of the ACF of white noise (blue line). Since the autocorrelation of the residuals is similar to the one of white noise, the model is considered statistically significant.

Fig. 7 compares the measurements of the temperature of the FC with the 2 min ahead prediction of the identified thermal model, and it qualitatively shows that the prediction is able to track the measurements.

Table 1

The estimated parameters of the FC model.

\begin{tabular}{lll}
\hline Name & Mean & Standard error \\
\hline OCV & 144.2 & 0.89 \\
$\alpha$ & $-1.15 \times 10^{-1}$ & $4.95 \times 10^{-4}$ \\
$\beta$ & $1.01 \times 10^{1}$ & $1.91 \times 10^{-4}$ \\
$\delta$ & $-4.89 \times 10^{-1}$ & $2.82 \times 10^{-3}$ \\
$\gamma$ & $9.11 \times 10^{-3}$ & $3.40 \times 10^{-5}$ \\
$R s$ & $1.09 \times 10^{-1}$ & $4.89 \times 10^{-2}$ \\
$C s$ & $2.27 \times 10^{4}$ & $9.55 \times 10^{2}$ \\
$\sigma$ & $-9.07 \times 10^{-2}$ & $5.10 \times 10^{-3}$ \\
\hline
\end{tabular}




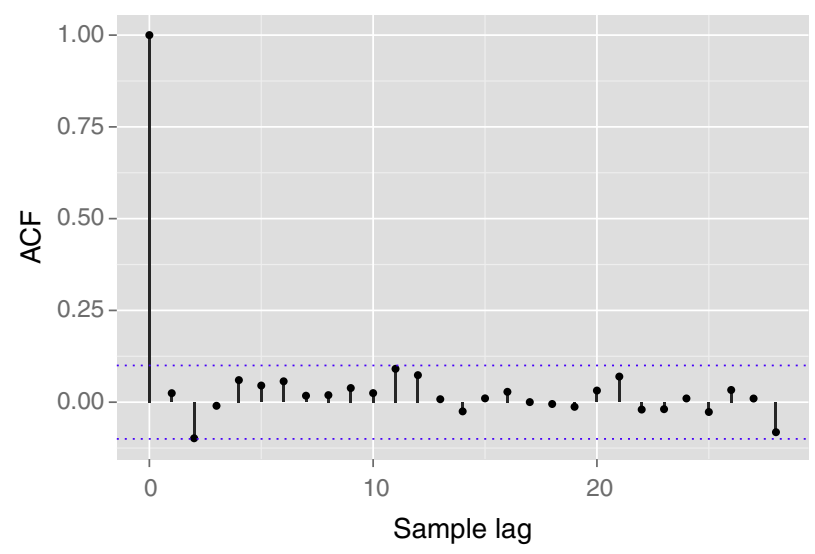

Fig. 6. Autocorrelation function (ACF) of the 1-step ahead predictions of the FC model and the $90 \%$ confidence interval of the ACF of white noise with the black and blue colors, respectively. (For interpretation of the references to color in this figure legend, the reader is referred to the web version of this article.)

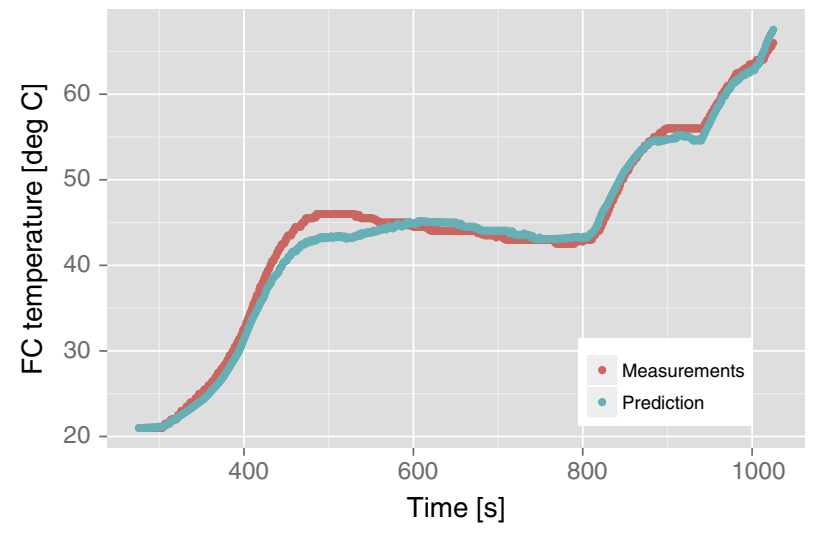

Fig. 7. The temperature of the FC stack according to the measurements and as predicted by the estimated thermal model ( 2 min ahead prediction).

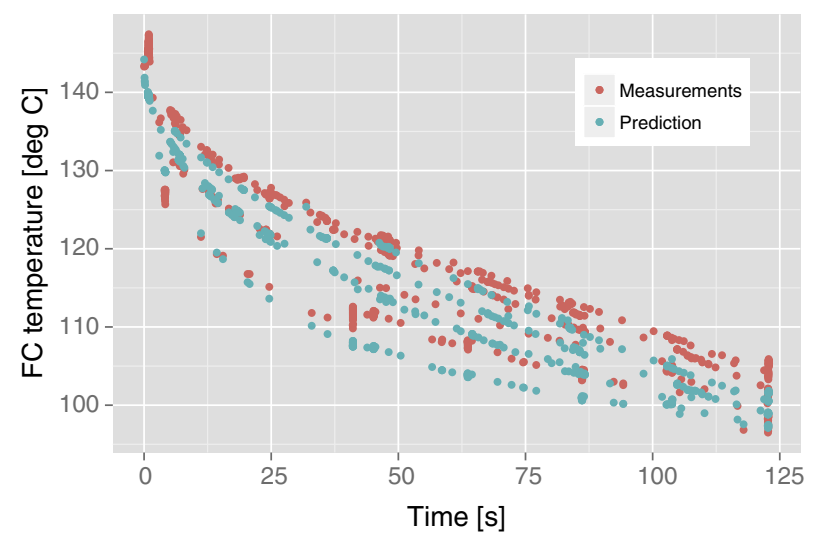

Fig. 8. The polarization curve of the FC according to the measurements and as predicted from the model of the FC voltage.

Fig. 8 compares the experimentally obtained polarization curve, i.e. FC voltage as a function of the FC current, with the one estimated using the identified electric model.

\section{Electrolyzer model}

The electrolyzer is a device that realizes the inverse process of a $\mathrm{FC}$, that is the production of pure hydrogen and oxygen through the electrochemical conversion of water. Nowadays, three mainstream electrolysis technologies are available: alkaline, PEM and SOFC. For this study, a PEM electrolyzer is chosen because it works at low temperature $\left(20-80^{\circ} \mathrm{C}\right)$ and allows a small size of the stack [27], thus is potentially suitable for small scale applications. In [28], a nearly linear function of the stack temperature is used to describe the efficiency of the conversion cycle. Since accurate measurements for estimating the thermal model of the electrolyzer are not available at this stage, the efficiency is assumed as a function of the current only. The adopted model is based on the measurements proposed in [29], which shows a positive correlation between the stack temperature and the conversion efficiency (similarly to the fuel cell) that, with a current of $100 \mathrm{~A}$, goes from $78 \%$ to $84 \%$ respectively at ambient and nominal temperature. We describe the voltage of the electrolyzer $v_{E L}$ as

$v_{E L}=33.1-43.0 \times 10^{-3} i_{E L}$,

where $i_{E L}$ is the current absorbed by the electrolyzer. In a similar way as done for the FC, the heat associated to the operation of the electrolyzer $Q_{E L}$ is calculated as the Joule loss associated with the model of the voltage, that is

$Q_{E L}=i_{E L}^{2} \cdot 43.0 \times 10^{-3}$.

\section{Tank model}

As known, the mass $m[\mathrm{~kg}]$ of a generic gas inside a tank is given as

$m=\int \dot{m}_{\text {in }}-\dot{m}_{\text {out }} d t$,

where $\dot{m}_{\text {out }}$ and $\dot{m}_{\text {in }}$ denote the outlet and inlet flow of the gas in $\left[\mathrm{kg} \mathrm{s}^{-1}\right]$, respectively. Assuming the gas as ideal, the pressure $p$ of the gas can be expressed with the law of the perfect gas as

$p=\frac{m \bar{R} T}{V}$,

where $R$ is the specific gas constant $\left[\mathrm{J} \mathrm{kg}^{-1} \mathrm{~K}^{-1}\right], V$ is the volume of the tank $\left[\mathrm{m}^{3}\right]$, and $T$ is the gas temperature [K]. Replacing Eq. (16) into Eq. (17) gives

$p=\frac{\bar{R} T}{V} \int \dot{m}_{\text {in }}-\dot{m}_{\text {out }} d t$

Based on the fact that the only possible path for the electrons is the FC membrane, the inlet and outlet flows of the hydrogen can be computed as a function of the electrolyzer and FC currents $i_{E L}$ and $i_{\mathrm{FC}}$ :

$\dot{m}_{\text {in }}=n_{E L} \frac{i_{E L}}{F}$,

$\dot{m}_{\text {out }}=n_{\mathrm{FC}} \frac{i_{\mathrm{FC}}}{F}$,

where $n_{E L}$ and $n_{F C}$ are the number of cells of the stack of the electrolyzer and FC, respectively. The complete model of the hydrogen tank is shown in Eq. (21) $\left(\bar{R}=4.124 \mathrm{~J} \mathrm{~g}^{-1} \mathrm{~K}\right)$.

$p_{H_{2}}=1 \times 10^{-3} \frac{\bar{R} T}{\overline{F V}} \int n_{E L} i_{E L}-n_{F C} i_{F C} d t$.

The model of the tank of the oxygen can be obtained in a similar way as done for the hydrogen. Although, the models of the tank and compressor of the oxygen are not implemented because the consumption and production rates of the oxygen are determined by the stoichiometric coefficients of the water reaction formula $\left(2 \mathrm{H}_{2}+\mathrm{O}_{2} \rightarrow 2 \mathrm{H}_{2} \mathrm{O}\right)$, and, as far as the formulation of the MPC is 
concerned, they can be implemented using algebraic relationships rather than dynamic ones.

\section{Compressor model}

The derivative of the isoentropic compression work required to compress the mass flow rate $\dot{m}$ at temperature $T_{\text {env }}[\mathrm{K}]$ from pressure $p_{1}$ to $p_{2}[\mathrm{~Pa}]$ is given as

$\dot{W}_{\text {isoen }}=\dot{m} \bar{R} T_{\text {env }} \frac{k}{k-1}\left({\frac{p_{2}}{p_{1}}}^{\frac{k-1}{k}}-1\right)$,

where $k$ is the adiabatic index $(\approx 1.4)$, and $\bar{R}\left[\mathrm{~J} \mathrm{~kg}^{-1} \mathrm{~K}^{-1}\right]$ is the specific constant of the gas that undergoes the compression. The mechanical power required for the compression is defined as

$\dot{W}_{\text {mech }}=\frac{\dot{W}_{\text {isoen }}}{\eta_{\text {isoen }}}$,

where $\eta_{\text {isoen }}$ is the isoentropic efficiency of the compressor. Using the same approach as in [30,31], $\eta_{\text {isoen }}$ is assumed constant at 0.8 . Finally, the electric power needed to drive the compressor is

$P_{c o}=\dot{W}_{\text {mech }} \frac{1}{\eta_{m}}$,

where $\eta_{m}=0.9$ is the lumped efficiency of the electric motor that drives the compressor. In a similar way as done for the tank, the mass flow rate $\dot{m}$ in Eq. (22) can be calculated as function of the electrolyzer current. The final expression of the compressor model is thus given as

$P_{c o}=n_{E L} \frac{i_{E L}}{F} \bar{R} T_{\text {env }} \frac{k}{k-1}\left({\frac{p_{2}}{p_{1}}}^{\frac{k-1}{k}}-1\right) \frac{1}{\eta_{m}}$,

with $\bar{R}=4.124 \mathrm{~J} \mathrm{~g}^{-1} \mathrm{~K}$.

\section{Building thermal model}

The building indoor temperature, say $T(t)\left[{ }^{\circ} \mathrm{C}\right]$, is described by the following first order differential equation [32]:

$C \frac{d T(t)}{d t}=-\frac{1}{R} T(t)+\frac{1}{R} T_{\text {out }}(t)+A \phi_{s}(t)+\phi_{h}(t)$,

where $T_{\text {out }}$ is the outdoor temperature $\left[{ }^{\circ} \mathrm{C}\right], \phi_{s}$ is the solar radiance on the horizontal plane $\left[\mathrm{W} \mathrm{m}^{-2}\right], \phi_{h}$ is the heat supplied to the building [W], and the parameters $C, R, A$ are the lumped thermal capacity of the building, the thermal resistance of the building envelope and the windows surface, respectively. The values and units of the parameters are shown in Table 2. According to the energy replacement strategy, the heat supplied to warm the building is composed by the following terms

$\phi_{h}(t)=P(t)+Q_{c}(t)+Q_{E L}(t)+Q_{e x t}(t)$,

where $P(t)$ is the electric power consumption of the heaters, $Q_{c}(t)$ is the heat extracted by the active cooling system of the FC, $Q_{E L}$ is the waste heat associated with the operation of the electrolyzer and $Q_{e x t}$ is the natural thermal loss of the FC. It is worth noting that a more accurate description of the dynamics of the building temperature could be achieved using a second order model because it allows to account for the different transients due to thermal masses

Table 2

The parameters of the building thermal model [32]

\begin{tabular}{lll}
\hline Name & Unit & Value \\
\hline$C$ & $\mathrm{~J}^{\circ} \mathrm{C}^{-1}$ & $1.23 \times 10^{7}$ \\
$R$ & ${ }^{\circ} \mathrm{C} \mathrm{W}^{-1}$ & $4.87 \times 10^{-3}$ \\
$A$ & $\mathrm{~m}^{2}$ & 10.7 \\
\hline
\end{tabular}

of the building envelope and air [33]. However,the main focus of this study is on describing the lumped thermal capacity of the building rather than a detailed description of the temperature transients, hence the first order model is used.

\section{Energy replacement model predictive control}

The objective of the MPC strategy is to schedule the operation of the resources of the energy replacement setup minimizing the total cost of operation, while obeying the constraints of the components and respecting the temperature comfort of the consumer. The symbols used in this section are defined in Tables 3 and 4. The former table defines the variables of the optimization problem (state variables and decision variables), while the latter summarizes the parameters.

The cost expression of the optimization underlaying the MPC problem is given as

$$
\begin{aligned}
J= & \sum_{k=0}^{N}\left[-P_{F C, k}+P_{E L, k}+2 P_{c o, k}+P_{k}\right] p_{k} \\
& +\sum_{k=0}^{N}\left(s_{k} S_{k}+\lambda_{k}\left[n_{k}-n_{\max }\right]\right),
\end{aligned}
$$

where $s_{k}$ and $\lambda_{k}$ are weights. In Eq. (28), the first summation is the total electricity cost and is calculated as the net power consumption times the electricity price: in this case, the electric power required to compress the oxygen is approximated with the one required for the hydrogen. In the second summation of Eq. (28), the first term accounts for the FC startup cost $\left(S_{k} \in\{0,1\}\right.$ is 1 when the FC state goes from off to on, 0 vice versa) and the second term is a soft constraint that penalizes those schedules that require the FC to go through more than $n_{\max }$ off-on cycles. The startup variable $S_{k}$ is calculated as following

$S_{k}=\operatorname{sgn}\left(i_{F C, k} \cdot\left(i_{F C, k}-i_{F C, k-1}\right)\right)$.

The FC power $P_{F C}(k)$ in Eq. (28) is expressed as

Table 3

Variables of the MPC optimization problem.

\begin{tabular}{llll}
\hline Symbol & Description & Type & Unit \\
\hline$T$ & Building indoor temperature & State variable & ${ }^{\circ} \mathrm{C}$ \\
$T_{F C}$ & FC stack temperature & State variable & ${ }^{\circ} \mathrm{C}$ \\
$Q_{C}$ & heat extracted by the FC cooling system & Decision variable & $\mathrm{W}$ \\
$i_{F C}$ & FC current & Decision variable & $\mathrm{A}$ \\
$v_{F C}$ & FC stack voltage & Variable & $\mathrm{V}$ \\
$i_{E L}$ & Electrolyzer current & Decision variable & $\mathrm{A}$ \\
$v_{E L}$ & Electrolyzer voltage & Variable & $\mathrm{V}$ \\
$p_{H_{2}}$ & hydrogen pressure in the tank & State variable & bar \\
$P_{C o}$ & Compressor electric power & State variable & $\mathrm{W}$ \\
$S$ & Fuel cell start-up & State variable & - \\
$n$ & Fuel cell start-up counter & Integer variable & - \\
\hline
\end{tabular}

Table 4

Parameters of the MPC optimization problem.

\begin{tabular}{llll}
\hline Symbol & Description & Value & Unit \\
\hline$T_{F C, M A X}$ & FC nominal stack temperature & 75 & ${ }^{\circ} \mathrm{C}$ \\
$i_{F C, M A X}$ & FC maximum current & 150 & $\mathrm{~A}$ \\
$i_{E L, M A X}$ & Electrolyzer maximum current & 120 & $\mathrm{~A}$ \\
$p_{\mathrm{H}_{2}, M A X}$ & Max hydrogen pressure in the tank & 6 & $\mathrm{bar}$ \\
$p_{\mathrm{H}_{2}, M I N}$ & Min hydrogen pressure in the tank & 2.1 & $\mathrm{bar}$ \\
$V$ & Tank volume & 2.5 & $\mathrm{~m}^{3}$ \\
$N$ & Optimization horizon length & 50 & $\mathrm{~h}$ \\
$n_{\max }$ & Maximum fuel cell off-on cycles & 3 & times/day \\
$p$ & Dynamic electricity price & & \\
\hline
\end{tabular}


$P_{F C, k}=v_{F C, k} i_{F C, k}$,

where $v_{F C}$ is determined using the FC voltage model (given in Eq. (5)) and $i_{F C}$ is a decision variable of the optimization. In a similar way, the electrolyzer power $P_{E L, k}$ is

$P_{E L, k}=i_{E L, k} v_{E L, k}$,

where $v_{E L, k}$ is determined using the model in Eq. (14) and $i_{E L, k}$ is a decision variable of the optimization. Finally, the compressor power $P_{c o}$ in Eq. (28) is expressed using the compressor model in Eq. (25).

The operational constraints implemented in the MPC are the following self-explanatory inequalities:

$0 \leqslant i_{F C}(k) \leqslant i_{F C, M A X}$

$0 \leqslant i_{E L}(k) \leqslant i_{E L, M A X}$,

$p_{\mathrm{H}_{2}, \mathrm{MIN}} \leqslant p_{\mathrm{H}_{2}}(k) \leqslant p_{\mathrm{H}_{2}, \mathrm{MAX}}$,

$T_{F C}(k) \leqslant T_{F C, M A X}$,

$i_{F C}(k+1)-i_{F C}(k) \leqslant \Delta i_{F C, M A X}$

$P_{\text {MIN }} \leqslant P(k) \leqslant P_{\text {MAX }}$

$T_{M I N} \leqslant T(k) \leqslant T_{M A X}$

which apply for $k=0, \ldots, N$. The inequality (35) limits the temperature of the FC: this task is accomplished through $Q_{c}$, which is a decision variable of the optimization problem. The comfort of the user is preserved by the pair of inequalities in (38).

In addition to the operational constraints, the optimization problem is subject to the mathematical models previously introduced, in particular:

- the FC operation is described by the models of the stack voltage, the heat loss and the stack temperature, which are given in Eqs. (5), (13) and (12), respectively.

- the electrolyzer operation is described by the models of the voltage and heat loss, given in Eqs. (14) and (15), respectively;

- the tank is described by the dynamic model in Eq. (21);

- the electric power consumption of the compressor for the hydrogen is described by the model in Eq. (25);

- the temperature of the building is described by the dynamic model in Eq. (26).

The dynamic models are discretized using rectangular integration and with a sample time of $200 \mathrm{~s}$. The MPC problem is given by minimizing the cost expression $J$ in Eq. (28) using $i_{F C}, i_{E L}, P$ and $Q_{c}$ as decision variables. The optimization problem if of non linear mixed integer type, is formulated in GAMS and solved using CONOPT algorithm.

\section{Results}

In this section, the simulations results of the energy replacement MPC are presented. In order to show the achieved cost savings and the capability of the proposed strategy to manage the larger amount of flexibility, a traditional MPC setup is used as a benchmark. The traditional MPC setup is a building equipped with electric space heating that is controlled by the same MPC as the energy replacement, but without any CHP unit. In the following, the traditional MPC setup and the energy replacement MPC will be referred to as Setup $A$ and Setup B, respectively. In the simulations, measured values of the outdoor temperature and insulation are utilized (sunny early spring period, ambient temperature between 2 and $6{ }^{\circ} \mathrm{C}$ and maximum peak insulation on the horizontal plane $\left.500\left[\mathrm{~W} \mathrm{~m}^{-2}\right]\right)$. Simulations are performed assuming a deterministic context, i.e. all the forecast required by the MPC are known and the models are error free. Simulations are performed using, initially, an artificial price signal and, subsequently, using the regulating power price of the Nord Pool day-ahead market.

\section{Artificial electricity price}

Following the same approach proposed in [34], the flexibility of the two setups is probed using a sine wave as an artificial price signal. Three price signal scenarios are analyzed, and each of them is characterized by a different frequency of the sine wave. The price signal scenarios are shown from Figs. 9-11 and they correspond to a period of the price signal of 5,14 and $50 \mathrm{~h}$, respectively.

Figures from Figs. 12-17 show the simulation results for each price signal scenario and setup. Each figure is composed by two stacked plots; the plot in the upper panel shows the building temperature (blue profile) and the temperature comfort range (red profile), which is chosen as $20 \pm 1{ }^{\circ} \mathrm{C}$ and $20 \pm 1.5^{\circ} \mathrm{C}$ during the day and night hours, respectively; the plot in the bottom panel shows the net power consumption of the building: negative values indicate that the building exports power to the grid and vice versa. In Scenario I, the price signal (Fig. 9) exhibits fast variations, and, in both setup, the respective MPC strategies are to able to shift the consumption during the periods when the cost the electricity is low while keeping the average temperature of the building in the middle of the comfort zone.

In the case of Scenario II, the variations of the price signal are slower than the previous case. The MPC controller of Setup A let the temperature of the building to lay at the lowest allowed limit

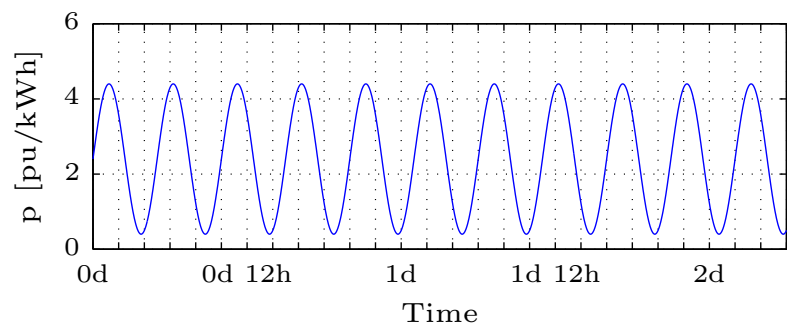

Fig. 9. The price signal of Scenario I.

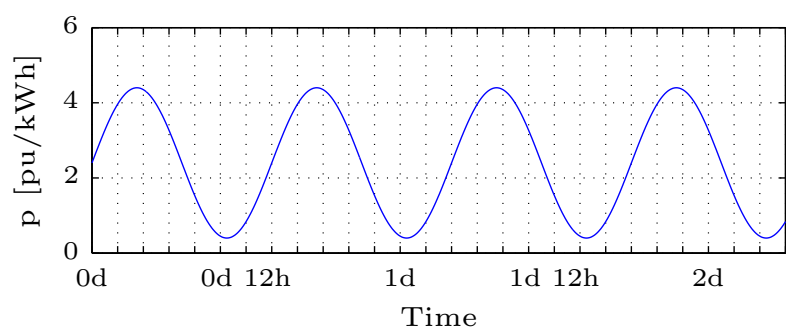

Fig. 10. The price signal of Scenario II.

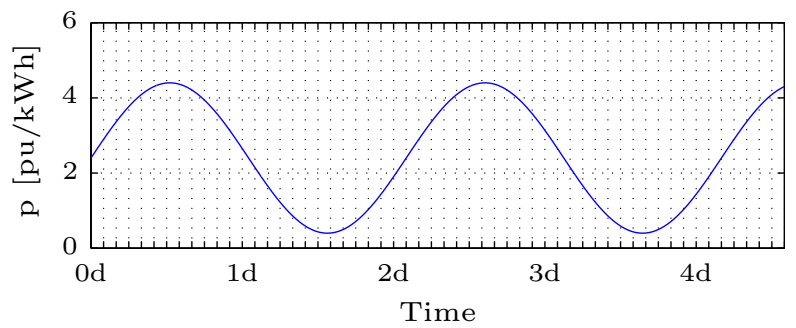

Fig. 11. The price signal of Scenario III. 
Building temperature

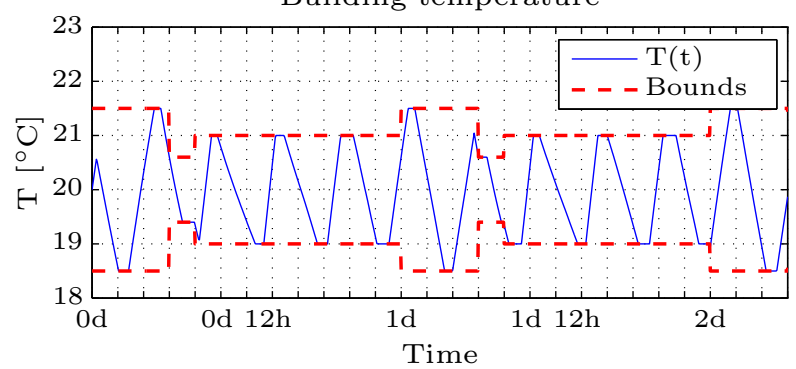

Total power consumption

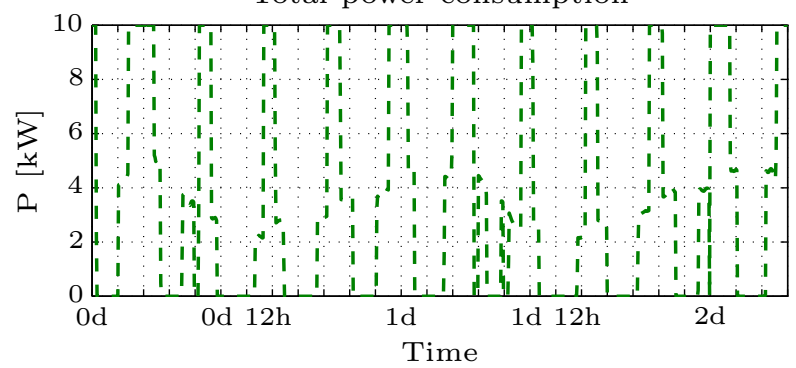

Fig. 12. Scenario I, Setup A.

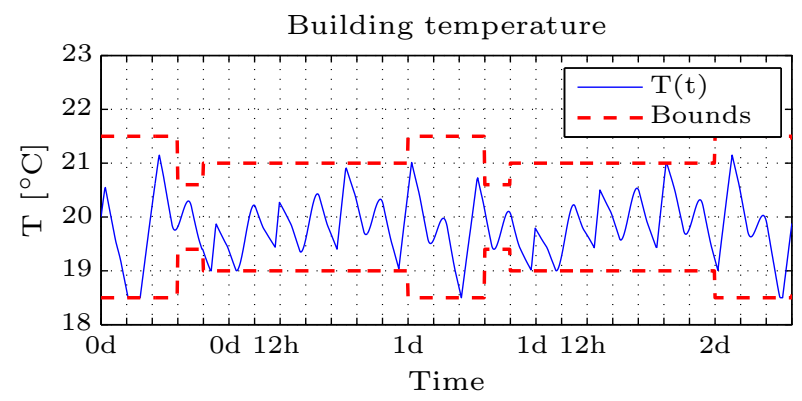

Total power consumption

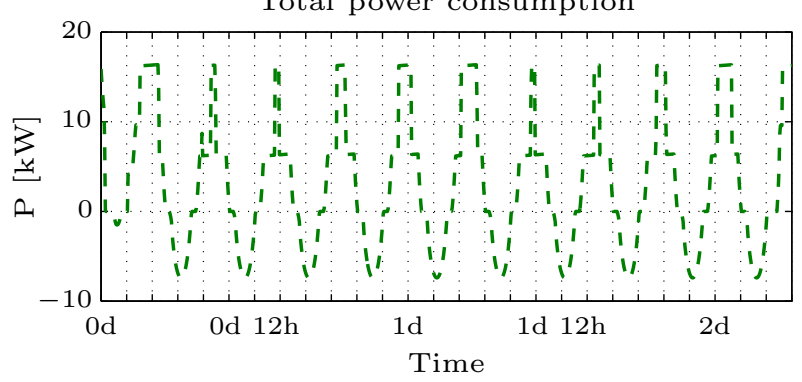

Fig. 13. Scenario I, Setup B.

during the periods with higher electricity cost, while, when the price is lower, it stores energy in the thermal mass by increasing the temperature of the building (Fig. 14). In the case of Setup B, the extended flexibility provided by the CHP system allows the controller to keep the average temperature of the building in the central part of the comfort area, as shown in Fig. 15.

Finally, scenario III is characterized by a slow varying price signal. The MPC controllers of both setup are able to modulate the power consumption according to the amplitude of the price signal. In comparison to the previous scenario, the temperature dynamics of Figs. 16 and 17 are similar because, since the electricity price varies slowly, the limited thermal mass of the building do not
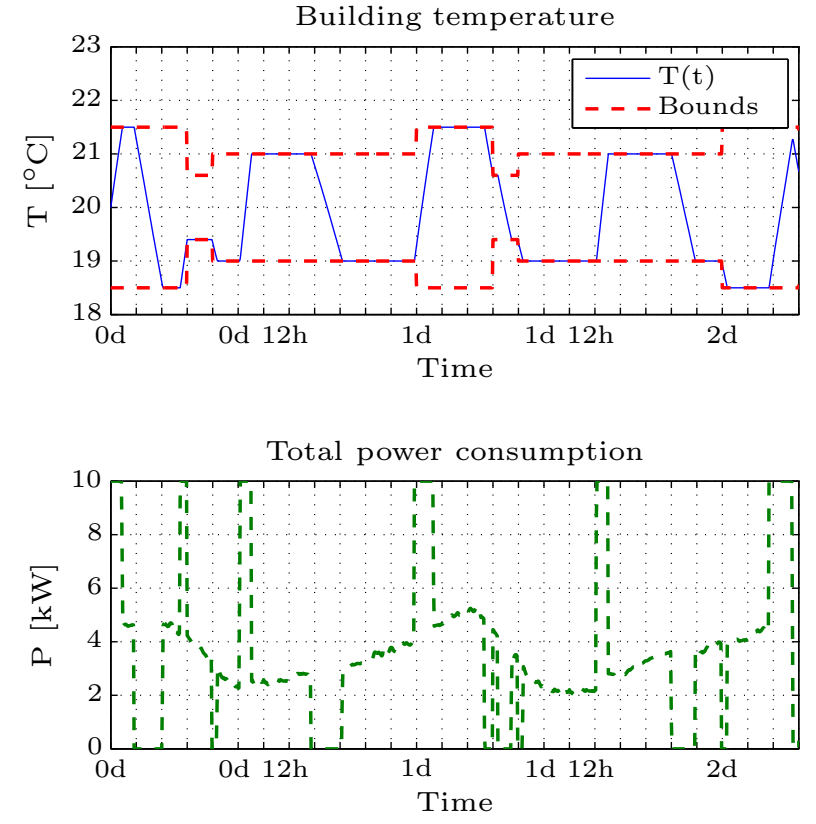

Fig. 14. Scenario II, Setup A.
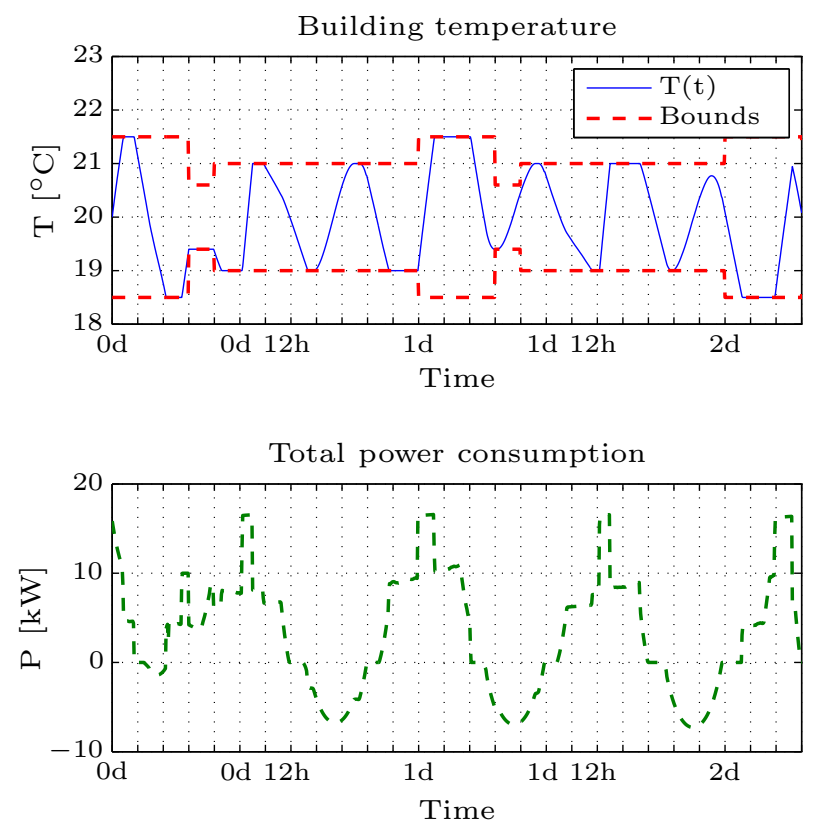

Fig. 15. Scenario II, Setup B.

allow to maintain the temperature in the middle of the comfort zone. In both Setup A and B, the controllers saturate the storing capacity of the building and let the temperature to lay at the limits of the comfort zone.

In order to evaluate in a numerical form the flexibility of the two setups, we evaluate the correlation index between the price signal and the power consumption. The correlation index is defined as

$r=\frac{\operatorname{Cov}[p, P]}{\sqrt{\operatorname{Var}[p] \cdot \operatorname{Var}[P]}}$,

where $P$ is the total net power consumption of the building and $p$ is the price signal. The correlation index is used as an indicator for measuring how much the power consumption is affected by the 

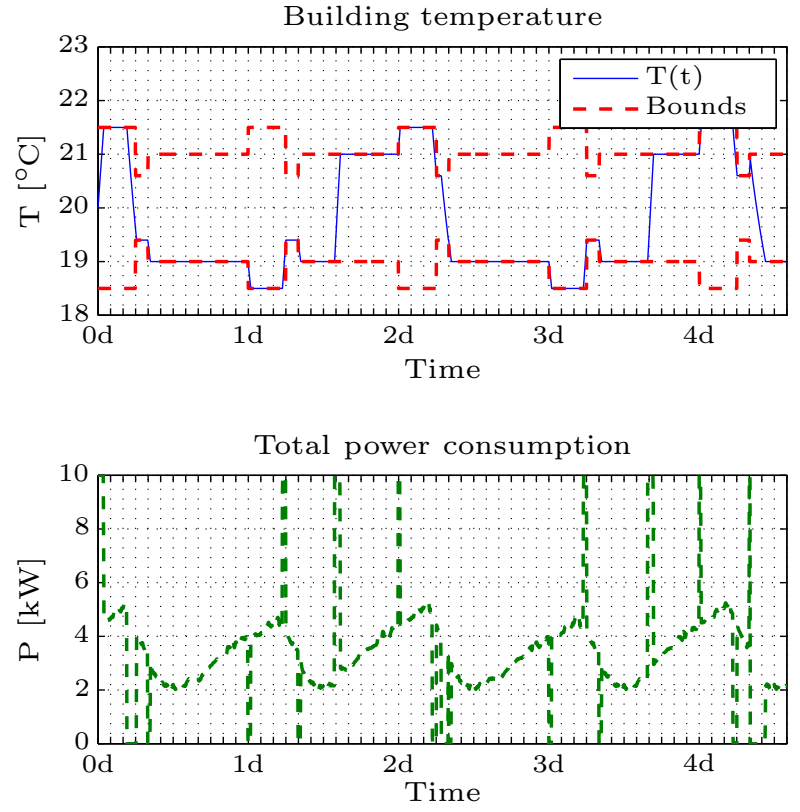

Fig. 16. Scenario III, Setup A.
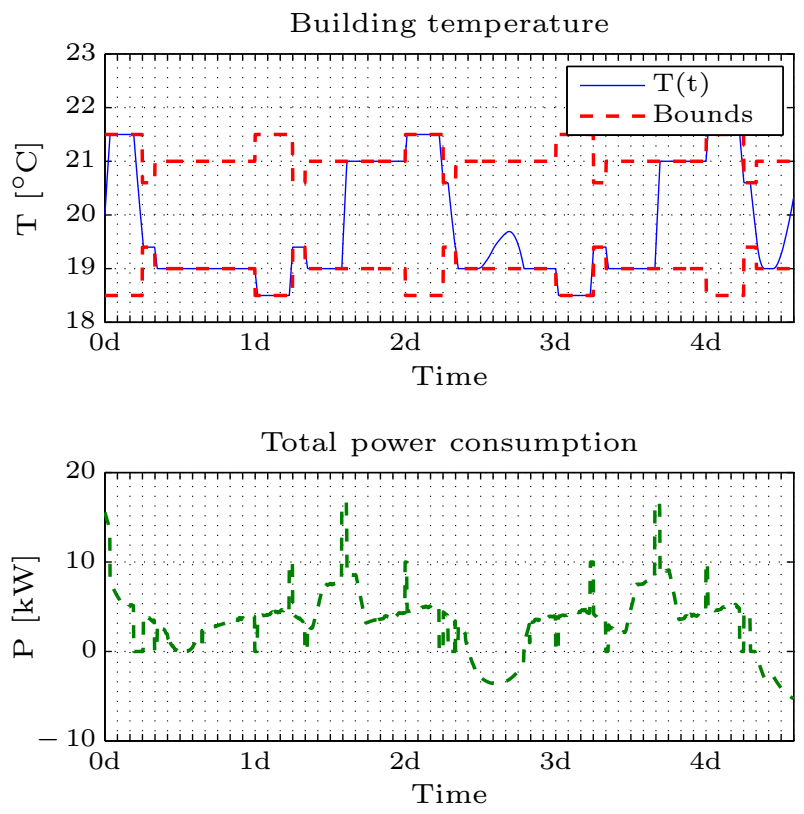

Fig. 17. Scenario III, Setup B.

variation of the electricity cost. For an ideal fully deferrable load, the correlation coefficient should be -1 , because the power consumption is always in anti-phase with the price signal. In the case of a conventional electric load, the flexibility is a function of the consumer comfort, and the value of the correlation coefficient is expected to assume larger values than -1 . The correlations coefficients calculated the three price signal scenarios are given in Table 5. As expected, the power consumption of Setup B has considerable larger negative correlation of the price signal than Setup A, meaning that the proposed energy replacement strategy is able to schedule the operation of the different energy resources and exploit the larger amount of flexibility.

In order to illustrate more into details the operation of the energy replacement setup, the power consumption profiles and
Table 5

The correlation indexes between the power consumption and the price signal calculate with Eq. (39).

\begin{tabular}{llll}
\hline Setup & SI & SII & SIII \\
\hline Setup B & -0.91 & -0.81 & -0.67 \\
Setup A & -0.82 & -0.48 & -0.22
\end{tabular}

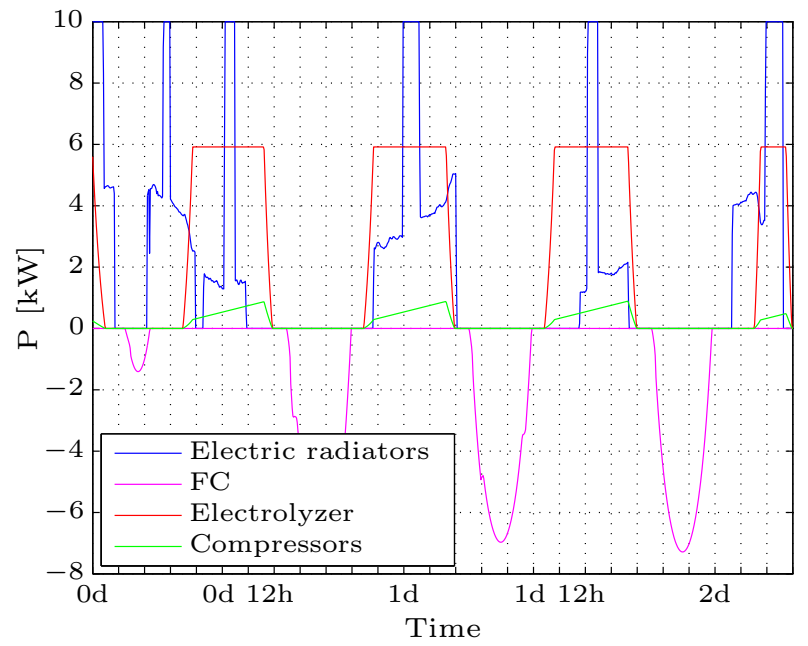

Fig. 18. The operation of the energy replacement setup (Setup B) during Scenario II: the power profiles.

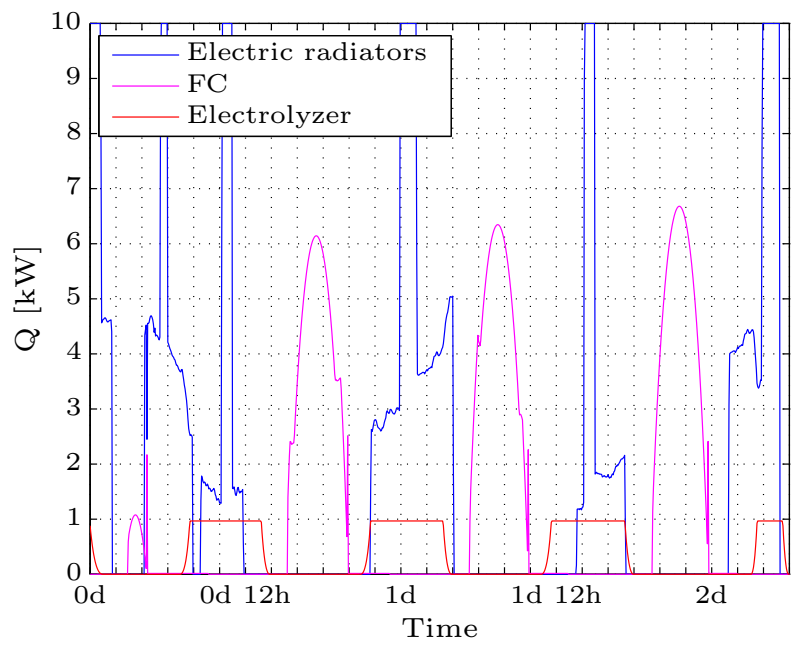

Fig. 19. The operation of the energy replacement setup (Setup B) during Scenario II: the heat profiles.

the contributions of heat of the energy resources of Setup B is shown in Figs. 18 and 19, respectively. In the former figure, it can be seen that when the electricity price is low, the electric radiators and the electrolyzer sustain the space heating of the building, and the compressors are activated in order to store the reactants. On the contrary, when the electricity price is large, the FC is activated in order to export electric power to the grid and provide space heating to the building.

\section{Nord Pool market electricity price}

The simulations of this section are performed using the hourly electricity price of the Nord Pool day-ahead market [35]. The electricity price is shown in Fig. 20. 


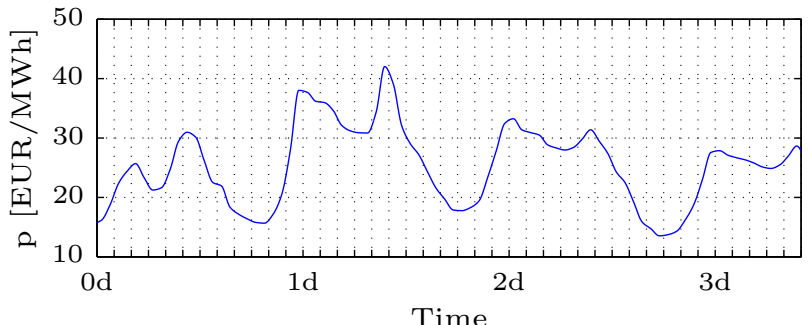

Fig. 20. The hourly electricity price of the Nord Pool day-ahead market. The initial instant of time refers to the 4th of August.
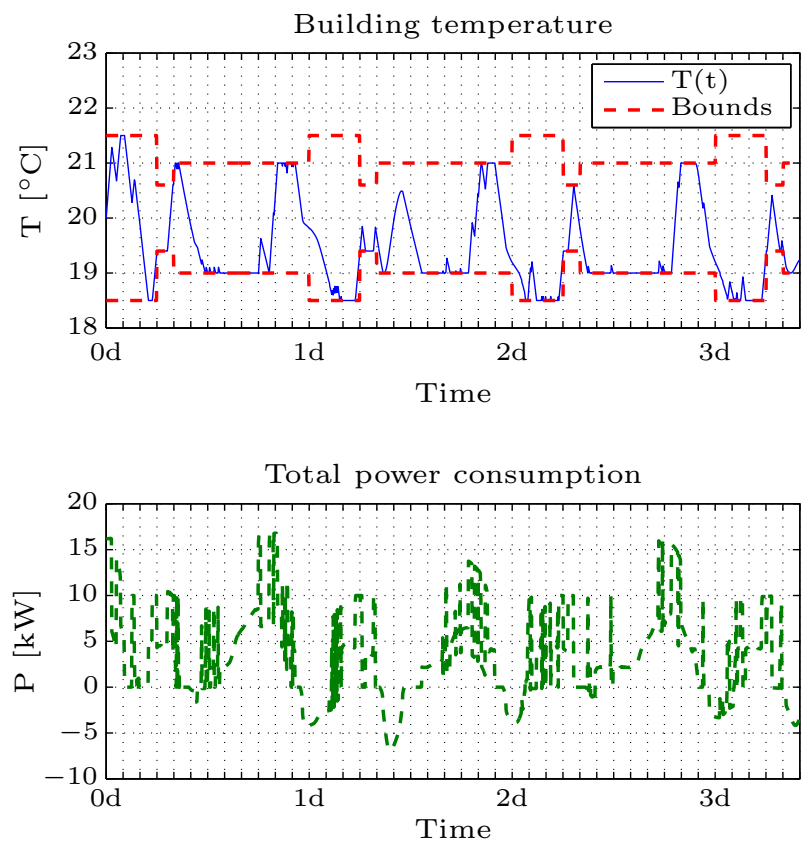

Fig. 21. Energy replacement strategy (Setup B) with the Nord Pool electricity price.
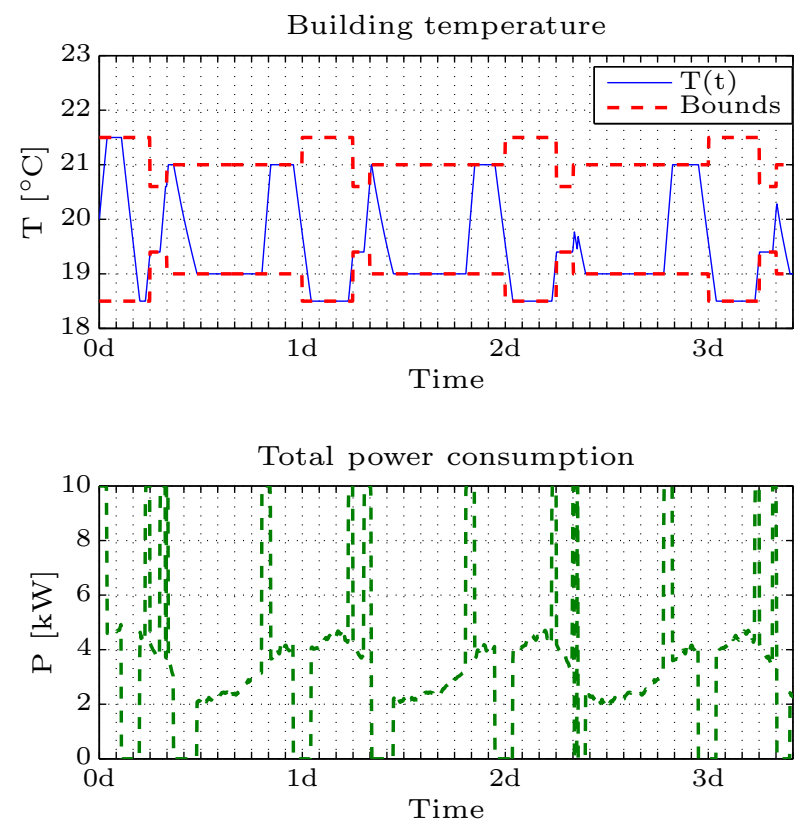

Fig. 22. Setup A with the Nord Pool electricity price.
Table 6

The total electricity cost calculated using the Nord Pool regulating power price of Fig. 20.

\begin{tabular}{ll}
\hline Setup & Electricity cost [EUR] \\
\hline Setup B (energy replacement MPC) & 7.27 \\
Setup A (MPC with only electric radiators) & 9.10 \\
Setup A' (thermostatic controlled radiators) & 9.70 \\
\hline
\end{tabular}

Fig. 21 shows the temperature profile and the net power consumption of the building controlled with the energy replacement MPC, while Fig. 22 shows the temperature dynamics for Setup A.

Table 6 summarizes the total electricity cost for Setup A, Setup $B$ and Setup $A^{\prime}$, which is the same as Setup A except that the radiators are controlled by a thermostatic controller rather than the MPC. From Table 6, it can be seen that the proposed energy replacement setup allows to save the $20 \%$ and $25 \%$ if compared to Setup A and Setup A', respectively.

\section{Conclusions}

A model predictive control strategy with the objective of exploiting the potential of combined heat and power generation of a fuel cell and an electrolyzer system was presented. This application was referred to as energy replacement to indicate the possibility of the consumer to switch among the most convenient source to provide space heating to a smart building according to a dynamic electricity price, which reflects the need of regulating power of the electric grid. We showed that the proposed model predictive control strategy is able to schedule effectively the operation of the different energy resources and outperforms other space heating setups in terms of amount of regulating power that can provide to grid and operation cost, which is reduced of up to $25 \%$. In the process of generating these results, this paper presents a novel PEMFC model suitable for smart-grid and micro-grid applications. The model has been realizing applying grey-box methodology using measurements from the $15 \mathrm{~kW}$ PEMFC of the EPFL-DESL facility. As a summary, the key contributions of the paper are:

- the concept of energy replacement, which offers a larger flexibility than conventional space heating setup and enhances the support that flexible demand can provide to the future power system;

- a model predictive control strategy for combining the operation of conventional heating system and combined heat and power generation devices;

- a novel grey-box model of a PEMFC suitable for smart and micro-grid applications.

\section{References}

[1] Ela E, Tuohy A, Milligan M, Kirby B, Brooks D. Alternative approaches for incentivizing the frequency responsive reserve ancillary service. Electr 2012;25(4):88-102. http://dx.doi.org/10.1016/j.tej.2012.04.015. <http:// www.sciencedirect.com/science/article/pii/S1040619012000929>.

[2] Xu Z, Ostergaard J, Togeby M. Demand as frequency controlled reserve. IEEE Trans Power Syst 2011;26(3).

[3] Affonso CM, da Silva LC. Potential benefits of implementing load management to improve power system security. Int J Electr Power Energy Syst 2010;32(6):704-10. http://dx.doi.org/10.1016/i.ijepes.2010.01.004. <http:// www.sciencedirect.com/science/article/pii/S014206151000013X>.

[4] Douglass P, Garcia-Valle R, Sossan F, Ostergaard J, Nyeng P. Design and evaluation of autonomous hybrid frequency-voltage sensitive load controller. In: IEEE international conference on innovative smart grid technologies (ISGT EUROPE), 4th IEEE/PES, 6-9 Oct. 2013. p. 1-5. http://dx.doi.org/10.1109/ ISGTEurope.2013.6695337. 
[5] Papaioannou IT, Purvins A, Tzimas E. Demand shifting analysis at high penetration of distributed generation in low voltage grids. Int J Electr Power Energy Syst 2013;44(1):540-6. http://dx.doi.org/10.1016/i.ijepes.2012.07.054. <http://www.sciencedirect.com/science/article/pii/S0142061512004140>.

[6] De Rijcke S, De Vos K, Driesen J. Balancing wind power with demand-side response. In: 5th IEEE joint IAS, PELS \& PES Benelux chapter young researchers symp, Leuven, Belgium; 2010.

[7] Corradi O, Ochsenfeld H, Madsen H, Pinson P. Controlling electricity consumption by forecasting its response to varying prices. IEEE Trans Power Syst 2013;28(1):421-9. http://dx.doi.org/10.1109/TPWRS.2012.2197027.

[8] Christakou K, Tomozei DC, Le Boudec JY, Paolone M. Gecn: primary voltage control for active distribution networks via real-time demand-response. IEEE Trans Smart Grid 2014;5(2):622-31. http://dx.doi.org/10.1109 TSG.2013.2275004.

[9] Halvgaard R, Poulsen N, Madsen H, Jørgensen J. Economic model predictive control for building climate control in a smart grid. In: IEEE international conference on innovative smart grid technologies (ISGT); 16-20 Jan. 2012. p.1-6. http://dx.doi.org/10.1109/ISGT.2012.6175631.

[10] Sossan F, Bindner H. A comparison of algorithms for controlling DSRs in control by price context using hardware-in-the-loop simulation. In: IEEE power and energy society general meeting; 22-26 July 2012. p.1-6. http:// dx.doi.org/10.1109/PESGM.2012.6345022.

[11] Zong Y, Kullmann D, Thavlov A, Gehrke O, Bindner H. Application of model predictive control for active load management in a distributed power system with high wind penetration. IEEE Trans Smart Grid 2012:3.

[12] Houwing M, Negenborn R, De Schutter B. Demand response with micro-chp systems. Proc IEEE 2011;99(1):200-13. http://dx.doi.org/10.1109/ IPROC.2010.2053831.

[13] Schug C. Operational characteristics of high-pressure, high-efficiency waterhydrogen-electrolysis. Int J Hydrogen Energy 1998;23(12).

[14] Kristensen NR, Madsen H. Continuous time stochastic modelling; 2003.

[15] Torregrossa D, Blumier D, Miraoui A. Regressive method for the determination of fuel cell pem parameters in order to develop a fuel cell pem emulator. In: Industry applications society annual meeting. IAS 2009. IEEE; 2009. http:/ dx.doi.org/10.1109/IAS.2009.5324869.

[16] Pukrushpan J. Modeling and control of fuel cell systems and fuel processors. $\mathrm{PhD}$ thesis, The University of Michigan; 2012.

[17] Rodatz S, Paganelli G, Guzzella L. Optimizing air supply control of a pem fuel cell system. In: Proceedings of the 2003 American control conference, 4-6 June 2003, vol. 3; 2003. p. 2043-8. http://dx doi.org/10.1109/ACC.2003.1243375.

[18] Pukrushpan J, Stefanopoulou A, Peng H. Modeling and control for pem fuel cell stack system. In: Proceedings of the American control conference, vol. 4; 2002. p. 3117-22. http://dx.doi.org/10.1109/ACC.2002.1025268.

[19] Sedghisigarchi K, Feliachi A. Dynamic and transient analysis of power distribution systems with fuel cells-part i: fuel-cell dynamic model. IEEE Trans Energy Convers 2004;19(2):423-8. http://dx.doi.org/10.1109/ TEC.2004.827039.

[20] Rekioua D, Bensmail S, Bettar N. Development of hybrid photovoltaic-fuel cell system for stand-alone application. Int $\mathrm{J}$ Hydrogen Energy 2014;39(3):1604-11. $\quad$ http://dx.doi.org/10.1016/i.ijhydene.2013.03.040. <http://www.sciencedirect.com/science/article/pii/S0360319913006496>.
[21] El-Sharkh M, Rahman A, Alam M, Byrne P, Sakla A, Thomas T. A dynamic model for a stand-alone $\{$ PEM $\}$ fuel cell power plant for residential applications. J Power Sour 2004;138(1-2):199-204. http://dx.doi.org/10.1016/ i.jpowsour.2004.06.037. <http://www.sciencedirect.com/science/article/pii/ S0378775304006925>.

[22] Deng L, Deng XR, Ma N, Wei P. Dynamic modeling of a pem fuel cell stack thermal system. In: 2010 2nd International conference on advanced computer control (ICACC), 27-29 March 2010, vol. 2; 2010. p. 473-7. http://dx.doi.org/ 10.1109/ICACC.2010.5486633.

[23] Fang L, Di L, Ru Y. A dynamic model of pem fuel cell stack system for real time simulation. In: Power and energy engineering conference (APPEEC); 27-31 March 2009. p. 1-5. http://dx.doi.org/10.1109/APPEEC.2009.4918046.

[24] Bjazic T, Ban Z, MPF. Linear model of PEM fuel cell power system for controller design purposes. In: 30th Jubilee international convention: computers in technical systems; 2007.

[25] Amphlett JC, Baumert R, Mann RF, Peppley BA, Roberge PR, Harris TJ Performance modeling of the ballard mark iv solid polymer electrolyte fuel cell i. Mechanistic model development. J Electrochem Soc 1995;142(1).

[26] Larminie J, Dicks A. Fuel cell systems explained. J. Wiley; 2003. ISBN 9780768012590. <http://books.google.dk/books?id=5rp22BEdibcC>.

[27] Carmo M, Fritz DL, Mergel J, Stolten D. A comprehensive review on pem water electrolysis. Int J Hydrogen Energy 2013;38(12):4901-34. http://dx.doi.org/ 10.1016/j.ijhydene.2013.01.151. <http://www.sciencedirect.com/science/ article/pii/S0360319913002607>

[28] Grgn H. Dynamic modelling of a proton exchange membrane (pem) electrolyzer. Int J Hydrogen Energy 2006;31(1):29-38. http://dx.doi.org/ 10.1016/j.ijhydene.2005.04.001. <http://www.sciencedirect.com/science/ article/pii/S0360319905000868>

[29] Dale N, Mann M, Salehfar H. Semiempirical model based on thermodynamic principles for determining proton exchange membrane electrolyzer stack characteristics. J Power Sour 2008;185(2):1348-53. http://dx.doi.org/10.1016/ j.jpowsour.2008.08.054. <http://www.sciencedirect.com/science/article/pii/ S0378775308016686>.

[30] Hovgaard T, Larsen LFS, Skovrup M, Bagterp Jø rgensen J. Power consumption in refrigeration systems-modeling for optimization. In: 2011 International symposium on advanced control of industrial processes (ADCONIP); 2011. p. 234-9.

[31] Lee JM, Cho B. A dynamic model of a pem fuel cell system. In: IEEE conference on applied power electronics; 15-19 Feb. 2009. p. 1-5. http://dx.doi.org/ 10.1109/APEC.2009.4802740.

[32] Bacher P, Thavlov A, Madsen H. Models for energy performance analysis. Tech rep, DTU-IMM; 2010.

[33] Madsen H, Holst J. Estimation of continuous-time models for the heat dynamics of a building. Energy Build 1995;22:67-79. http://dx.doi.org/ 10.1016/0378-7788(94)00904-X. <http://www.sciencedirect.com/science/ article/pii/037877889400904X>.

[34] Sossan F, Bindner $\mathrm{H}$. Evaluation of the performance of indirect control of many DSRs using hardware-in-the-loop simulations. In: IEEE conference on decision and control (CDC); 10-13 Dec. 2012. p. 5586-91. http://dx.doi.org/10.1109/ CDC.2012.6425881.

[35] Nord Pool Spot. Nord pool spot; 2013. <http://www.nordpoolspot.com/>. 